\title{
A Two-Stage ORC Integration to an Existing Fluidized Bed Sewage Sludge Incineration Plant for Power Production in the Scope of Waste-to-Energy
}

\author{
A. Abusoglu ${ }^{1 *}$, A. Tozlu ${ }^{2}$, A. Anvari-Moghaddam ${ }^{3,4}$ \\ ${ }^{1}$ Istanbul Technical University /Mechanical Engineering Department, Istanbul, 34437, Turkey \\ ${ }^{2}$ Bayburt University/Mechanical Engineering Department, Bayburt, 69000, Turkey \\ ${ }^{3}$ Aalborg University/Department of Energy Technology, Integrated Energy Systems Laboratory, Aalborg, 9220, Denmark \\ ${ }^{4}$ University of Tabriz/Faculty of Electrical and Computer Engineering, Tabriz, 5166616471, Iran \\ E-mails: abusoglu@itu.edu.tr, alperentozlu@ bayburt.edu.tr, aam@et.aau.dk
}

Received 13 September 2021, Revised 26 October 2021, Accepted 17 November 2021

\begin{abstract}
:
This paper presents the design, evaluation, and optimization of an electricity generation system based on the two-stage organic Rankine cycle (TS-ORC), which utilizes the waste heat of an existing fluidized bed sewage sludge incineration (FBSSI) facility. The facility incinerates an average of 300 tons per day of sewage sludge with a dry matter content of $22 \%$. After the drying process, the sewage sludge is burned in a fluidized bed combustor, and exhaust gas at a temperature of about $850-900^{\circ} \mathrm{C}$ is released due to the combustion. The system provides the energy required to dry the sludge from this exhaust gas. In this study, a TS-ORC is designed to be coupled to the exhaust gas flowlines discharged to the atmosphere at two different points in the FBSSI plant. The exergy efficiency of the FBSSI facility is found to be $70.5 \%$. Three different working fluids are selected to examine the variations of thermodynamic and thermoeconomic performance parameters of the designed TS-ORC system. The highest power generation in the TSORC system (183.40 kW) is achieved using R1234yf as working fluid. R1234yf is also the most expensive fluid for electricity generation among the other working fluids $(10.57 \$ / \mathrm{h})$. The least electricity generation in the TS-ORC $(142.70 \mathrm{~kW})$ occurs at the thermoeconomically most affordable cost with R245fa $(9.35 \$ / \mathrm{h})$.
\end{abstract}

Keywords: Fluidized bed sewage sludge incineration, ORC, thermodynamic, thermoeconomy, waste to energy, multiobjective optimization

\section{Introduction}

After successive treatment and stabilization processes in a wastewater treatment plant (WWTP), sewage sludge is kept in tightly closed, airless tanks for a specific retention period and at a certain temperature range to produce biogas by anaerobic digestion. Finally, the sewage sludge, which is subjected to a dewatering process before discharging it from the facility and whose dry matter content is increased to about $20 \%$, becomes ready for the disposal process. Sewage sludge incineration is one of the well-established disposal methods for municipal sewage sludge, and many researchers have conducted theoretical and experimental research on this issue since the 1980s [1-3]. In these early studies, it was reported that sewage sludge, which was discharged mostly to the seas or oceans in the 1970s, was disposed of by laying on agricultural lands in the 1980s or filling empty fields near cities. In developed countries, such as the USA, Canada, the $\mathrm{EU}$, and Japan, sewage sludge was stored in landfills following strict environmental standards to prevent groundwater contamination [1-2]. In the 1990s, it began to be emphasized that incineration of treatment sludge was the most appropriate solution in big cities and metropolises. Besides, the waste heat of incineration plants was proposed to be used in the small and medium-sized cogeneration plants to be established on the plant site [4]. However, one of the essential advantages of sewage sludge incineration plants in those years, as it is today, was the process of drying the sludge with the waste heat before burning to increase its dry matter content and achieve more efficient combustion.

Within the framework of the waste-to-energy (WtE) that started to develop in the early 2000 s, it became increasingly important to use the sewage sludge as a sustainable fuel. Thus, systematic investigations were started to reveal the thermal value of sewage sludge for efficient energy recovery [5]. Utilizing sewage sludge as a fuel in the cement industry was reported as a promising approach [6] because ash with heavy metal content sourced by the combustion process was bound to the clinker matrix during the reaction taking place higher than $1300^{\circ} \mathrm{C}$, which prevents the formation of another type of waste through this process [7]. To clarify the combustion characteristics of sewage sludge, a new type of pressurized fluidized bed incinerator coupled with a turbocharger was compared to a conventional type of incinerator. It was reported that at a daily incineration capacity of 100 tons, an energy savings of $50 \%$ were achieved with the pressurized fluidized bed incinerator compared to the conventional incineration. Also, the amount of fuel supply was reduced by $25 \%$ because of pressurization [8]. A separate simulation study supporting this result also showed that heat and mass transfers are enhanced, and consequently, incineration mechanisms are accelerated in fluidized bed incineration [9]. A large proportion of the previously published works available in the literature focused on energy recovery from sewage sludge during its 
disposal. Werther and Ogada [10] investigated the different burning methods of sewage sludge in the broadest sense. These methods include burning the sludge with pulverized coal as replenishment fuel and burning it with municipal solid waste. They also carried out detailed studies on the drying of the sewage sludge to increase its dry matter content to a certain volumetric percentage for more efficient combustion. In many pre-published studies, it was underlined that if sufficient scientific and technical infrastructure is established to incinerate sewage sludge with other wastes without any fossil fuel supply, incineration is a unique energy recovery method, highlighting the positive aspects for the environment [11-14]. Direct incineration of dried sewage sludge for use along with any fossil fuel in a power production plant or cement production as an auxiliary fuel was recently investigated by many scientists. Among these works, there are local/regional case studies in which energy is generated by drying and burning sewage sludge by various methods [15-18] and review studies on countries' energy recovery potentials by extensively investigating and revealing their sewage sludge inventories [19-21].

\subsection{Electricity Production with an ORC Coupled to the} Fluidized Bed Sewage Sludge Incineration (FBSSI) Plant

The principle of sewage sludge incineration in a fluidized bed boiler is based on moving the sludge particles whose dry matter ratio is increased to $40-60 \%$, upward direction into the air or gas stream in the boiler. Thus, the sludge particles suspended in the air stream in the boiler behave like a fluid, making the combustion process homogeneous and efficient. The combustion process takes place at low combustion temperatures in the fluidized bed (FB). The exhaust gas energy is first used to dry the sewage sludge until it reaches certain dryness range for efficient combustion. The incineration of sewage sludge in the fluidized bed incineration (FBI) systems enabled the energy required to dry the sludge and use the remaining energy in both district heating $(\mathrm{DH})$ and low-temperature electricity generation [22-27]. Considering these energy recovery possibilities results from the FBI's low thermal efficiency, the accumulation of sewage sludge at the bottom of the FB, and high emissions. The solutions were proposed to overcome the above problems using the energy obtained due to incineration in an environmentally beneficial recovery process for an effective sewage sludge disposal [28-31].

The organic Rankine cycle (ORC) usually generates electricity with low-temperature sources $\left(\geq 80^{\circ} \mathrm{C}\right)$. However, there are applications where ORCs are used with medium $\left(200-450^{\circ} \mathrm{C}\right)$ and high-temperature $\left(450^{\circ} \mathrm{C}\right.$ and above $)$ sources [32]. The heat of the combustion gas obtained in a fluidized bed sewage sludge incineration (FBSSI) unit is first transferred to the heat transfer oil for drying the sludge. The exhaust gas, whose temperature drops after this process, is a candidate for a unique, medium-temperature, and sustainable heat source for the ORC. The evaluation of the exhaust gas released due to the combustion of sewage sludge in the FBSSIs for electricity generation with the ORC was discussed partly in only a few published papers in the open literature [33-35]. On the other hand, waste heat obtained from WWTP or MSWP integrated into an ORC was extensively studied [36-40].

In this study, an ORC system is designed, which utilizes the exhaust gas sourced from an existing FBSSI plant. First, the incineration facility is introduced, then a detailed thermodynamic analysis and evaluation are presented using the facility's actual operating data. Then, a two-stage ORC system compatible with the existing facility's operating conditions is designed. Three different working fluids are selected to examine the variations of thermodynamic and thermoeconomic performance parameters of the designed ORC system. Finally, multi-objective optimization of the designed system is performed in MATLAB using the nondominated sorting genetic algorithm (NSGA-II) method. Considering the previously published works in the open literature, there are very few studies found on energy recovery based on sewage sludge incineration. In addition to the systematic analysis and optimization work performed in the presented study, using actual operating data based on an existing FBSSI facility constitutes the main motivation behind this study.

\section{Material and Method}

\subsection{Description of a Two-Stage ORC System Integrated to the Existing FBSSI Plant (TS-ORC)}

GASKI FBSSI plant is Turkey's first sewage sludge incineration facility, and considering the infrastructure needs of the city of Gaziantep, it was commissioned in 2012 for the incineration of a total of 300 tons of sludge per day with a dry matter content of $22 \%$. Sewage sludge collected from the three advanced biological WWTP of the city is first dried in the furnace and then burned in the FB incinerator resulting in ash. In the facility, first, thermal drying is applied to the sewage sludge, and the amount of dry matter in its content is increased to $40-50 \%$. It was reported by the facility management that the combustion efficiency reaches its highest value when the dry matter content of the sludge is between 50-60\%. After the drying process, the sewage sludge is burned in a fluidized bed boiler, and 10-12 tons of ash is produced per day while a temperature of about 850 $900^{\circ} \mathrm{C}$ of exhaust gas is released (state 17) due to the combustion. The system provides the energy required to dry the sludge from this exhaust gas. Natural gas is used as auxiliary fuel in the facility until the boiler temperature reaches $650^{\circ} \mathrm{C}$ during the combustion; then, when the temperature reaches $850-900^{\circ} \mathrm{C}$, it is possible to burn the sludge without the need for additional fuel. A flue gas purification system is used to prevent combustion gases from harming the environment (state 24 to 29). The result of the sludge incineration process is ash with a dry matter content of $99 \%$, in which the harmful pathogens inside are destroyed by burning the sludge cake while its volume is reduced by $90 \%$ and is entirely harmless to the environment. Ash produced as a result of the combustion in the facility is buried in the municipal solid waste land and eliminated (state 29). Similarly, the dust in the exhaust gas is eliminated by the filtration system (state 27).

In this study, a two-stage ORC system (TS-ORC) is designed to be coupled to the exhaust gas flowlines discharged to the atmosphere at two different points in the FBSSI plant. The first exhaust gas stream (state 1) enters the TS-ORC system at a temperature of $279.95^{\circ} \mathrm{C}$, a pressure of 1.013 bar and a mass flow rate of $5.268 \mathrm{~kg} / \mathrm{s}$ while the second stream (at state 11) enters the system at a temperature of $196.29^{\circ} \mathrm{C}$, a pressure of 1.077 bar, and a mass flow rate of $4.460 \mathrm{~kg} / \mathrm{s}$. The aim here is to generate electricity by using the thermal energy of the exhaust gas by providing a secondary benefit, apart from the main function of the FBSSI plant, where the sludge is first dried and then burned and thus completely disposed of. The flow schematic of the TS-ORC system integrated to FBSSI plant is given in Figure. 1. 


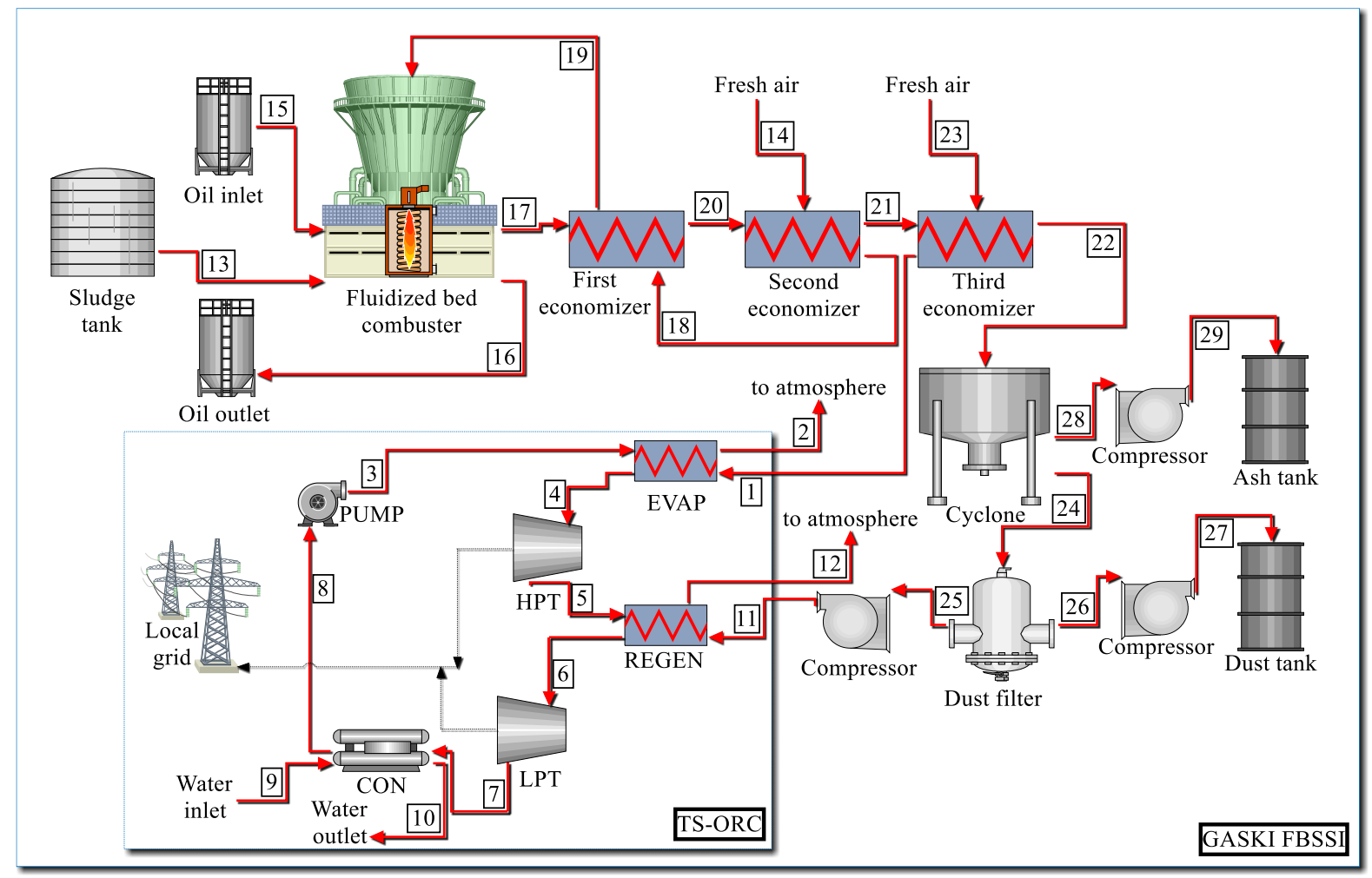

Figure 1. The flow schematic of the TS-ORC system integrated to an existing FBSSI plant

To use these different exhaust flows in the facility more efficiently together, the TS-ORC system is designed to include a two-stage turbine system. The TS-ORC system consists of an evaporator (EVAP), a high-pressure turbine (HPT), a regenerator (REGEN), a low-pressure turbine (LPT), a condenser (CON), and a pump (PUMP) (see Figure.1). As seen in Figure. 1, exhaust gas at a high temperature $\left(280^{\circ} \mathrm{C}\right)$ enters the evaporator (state 1$)$, where it is discharged into the atmosphere immediately after transferring its heat to the working fluid (state 2). On the other hand, exhaust gas at a low temperature $\left(196.3^{\circ} \mathrm{C}\right)$ enters the regenerator (state 11), where it transfers its heat to the working fluid exiting the HPT and then discharges into the atmosphere (state 12). The pressurized working fluid in a superheated steam phase provides the first power generation in HPT. Then, it enters REGEN and exchanges heat with the low-temperature exhaust gas before entering the LPT. The working fluid enters the LPT at the same temperature as it previously entered the HPT but at a lower pressure. After the final power generation occurs in LPT, the working fluid becomes condensed by transferring heat to water in $\mathrm{CON}$, then enters PUMP to be pressurized again. Thus, the cycle is complete. The TS-ORC system is designed so that the working fluid temperatures are the same at both turbine inlets. Also, the temperature values at which the exhaust gases leave the EVAP and REGEN are the same. In heat exchangers in the TS-ORC system, the difference between the outlet temperatures of hot fluids and the inlet temperatures of cold fluids is defined as $T_{x}$. This is because LMTD values are kept at reasonable levels and a suitable heat exchanger selection can be made. Design parameters for the TS-ORC are listed in Table 1.
Table 1. Design parameters of the TS-ORC [37]

\begin{tabular}{lll}
\hline Parameter & Symbol & Value \\
\hline Inlet temperature of heat source $1\left({ }^{\circ} \mathrm{C}\right)$ & $T_{1}$ & 279.95 \\
Outlet temperature of heat source $1\left({ }^{\circ} \mathrm{C}\right)$ & $T_{2}$ & 60 \\
Mass flow rate of heat source $1(\mathrm{~kg} / \mathrm{s})$ & $\dot{m}_{e x}$ & 5.268 \\
Inlet temperature of heat source $2\left({ }^{\circ} \mathrm{C}\right)$ & $T_{1}$ & 196.29 \\
Outlet temperature of heat source $2\left({ }^{\circ} \mathrm{C}\right)$ & $T_{2}$ & 60 \\
Mass flow rate of heat source $2(\mathrm{~kg} / \mathrm{s})$ & $\dot{m}_{e x}$ & 4.460 \\
Pressure ratio of TS-ORC & $P R$ & 10 \\
Temperature difference & $T_{X}$ & 15 \\
Inlet temperature of HPT $\left({ }^{\circ} \mathrm{C}\right)$ & $T_{4}$ & 181.3 \\
Exit temperature of HPT $\left({ }^{\circ} \mathrm{C}\right)$ & $T_{5}$ & 134.5 \\
Inlet temperature of LPT $\left({ }^{\circ} \mathrm{C}\right)$ & $T_{6}$ & 181.3 \\
Exit temperature of LPT $\left({ }^{\circ} \mathrm{C}\right)$ & $T_{7}$ & 165.4 \\
Isentropic efficiency of pump & $\eta_{P U M P}$ & 0.85 \\
Isentropic efficiency of turbines & $\eta_{T}$ & 0.85 \\
Effectiveness of heat exchangers & $\varepsilon f_{H E}$ & 0.85 \\
Inlet temperature of cooling water $\left({ }^{\circ} \mathrm{C}\right)$ & $T_{7}$ & 20 \\
Outlet temperature of cooling water $\left({ }^{\circ} \mathrm{C}\right)$ & $T_{8}$ & 42 \\
Ambient temperature $\left({ }^{\circ} \mathrm{C}\right)$ & $T_{0}$ & 20 \\
\hline
\end{tabular}

As explained previously in section 2.1 , ORCs can be designed to use the medium $\left(200-450^{\circ} \mathrm{C}\right)$ and hightemperature $\left(450^{\circ} \mathrm{C}\right.$ and above) sources. In this study, considering the average temperatures of two different exhaust gas flows of the FBSSI plant, that will be used as a heat source for the TS-ORC system, the system's thermal source temperature can be evaluated in the medium temperature range. For this, three different working fluids are chosen suitable for medium temperature sources. The properties of the selected working fluids are shown in Table 2.

Table 2. Properties of the selected working fluids for the TS-ORC

\begin{tabular}{ccccc}
\hline Fluid & Chemical formula & Mol. Weight $(\mathrm{kg} / \mathrm{kmol})$ & $P_{\text {crit }}(\mathrm{MPa})$ & $T_{\text {crit }}\left({ }^{\circ} \mathrm{C}\right)$ \\
\hline R245fa & $\mathrm{CF}_{3} \mathrm{CH}_{2} \mathrm{CHF}_{2}$ & 134 & 3.651 & 154 \\
R1234yf & $\mathrm{C}_{3} \mathrm{H}_{2} \mathrm{~F}_{4}$ & 114.04 & 3.382 & 94.7 \\
R1234ze & $\mathrm{CHF}=\mathrm{CHCF}_{3}$ (trans) & 114.04 & 3.635 & 109.4 \\
\hline
\end{tabular}


Table 3. The thermodynamic and thermoeconomic governing equations used in the analyses of the FBSSI plant and TSORC system.

\begin{tabular}{|c|c|c|c|}
\hline \multicolumn{2}{|c|}{ Thermodynamic relations } & \multicolumn{2}{|c|}{ Thermoeconomic relations } \\
\hline$\Sigma \dot{m}_{i}=\Sigma \dot{m}_{e}$ & $\begin{array}{l}\dot{m} ; \text { mass flow rate } \\
i ; \text { inlet, } e ; \text { exit }\end{array}$ & $\dot{Z}=(P E C * C R F * \phi) /(3600 * N)$ & $\dot{Z}$; capital cost rate \\
\hline & & $C R F=\frac{i_{r}\left(1+i_{r}\right)^{n}}{\left(1+i_{r}\right)^{n}-1}$ & $\begin{array}{l}C R F ; \text { capital recovery } \\
\text { factor }\end{array}$ \\
\hline$\dot{Q}-\dot{W}=\Sigma \dot{m}_{e} h_{e}-\Sigma \dot{m}_{i} h_{i}$ & $\begin{array}{l}Q ; \text { net heat transfer } \\
\dot{W} ; \text { net work transfer } \\
h \text {; enthalpy }\end{array}$ & $\begin{array}{l}\phi=1.06 \\
n=15 \\
N=8040 \\
i=15 \% \\
P E C_{E V A P}=130\left(A_{E V A P} / 0.093\right)^{0.78}\end{array}$ & $\begin{array}{l}\phi ; \text { maintenance factor } \\
n ; \text { total life time } \\
N ; \text { annual operation time } \\
i_{r} ; \text { interest rate }\end{array}$ \\
\hline $\begin{aligned} \dot{E} x_{\text {Heat }}-\dot{W}= & \Sigma \dot{m}_{e} \psi_{e} \\
& -\Sigma \dot{m}_{i} \psi_{i}+\dot{E} x_{D}\end{aligned}$ & $\begin{array}{l}\dot{E} x_{\text {Heat }} ; \text { net exergy transfer } \\
\psi ; \text { specific flow exergy }\end{array}$ & $\begin{array}{l}P E C_{R E G E N}=130\left(A_{R E G E N} / 0.093\right)^{0.78} \\
P E C_{C O N}=1773\left(\dot{m}_{w f}\right) \\
P E C_{\text {PUMP }}=3540\left(\dot{W}_{\text {PUMP }}\right)^{0.71} \\
P E C_{H P T \& L P T}=6000\left(\dot{W}_{\text {net }}\right)^{0.7}\end{array}$ & $\begin{array}{l}\text { PEC; Purchased } \\
\text { equipment costs } \\
w f ; \text { working fluid }\end{array}$ \\
\hline$\psi=\left(h-h_{0}\right)-T_{0}\left(s-s_{0}\right)$ & $\begin{array}{l}s ; \text { entropy } \\
T ; \text { Temperature } \\
0 ; \text { dead state }\end{array}$ & $\dot{Q}_{k}=U_{k} A_{k} L M T D$ & $\begin{array}{l}\dot{Q}_{k} ; \text { heat exchanger load } \\
A_{k} ; \text { heat transfer area } \\
k ; \text { component }\end{array}$ \\
\hline$\dot{E} x=\dot{m} \psi$ & $\dot{E} x$; Exergy rate & $U=0.7$ & $U$; heat transfer coefficient \\
\hline$\dot{W}_{n e t}=\dot{m}_{w f}\left[\left(h_{t, i}-h_{t, e}\right)-\left(h_{p, e}-h_{p, i}\right)\right]$ & $\dot{W}_{\text {net }} ;$ net power & $L M T D=\frac{\left(\left(T_{H, i}-T_{C, e}\right)-\left(T_{H, e}-T_{C, i}\right)\right)}{\ln \frac{\left(T_{H, i}-T_{C, e}\right)}{\left(T_{H, e}-T_{C, i}\right)}}$ & $\begin{array}{l}\text { LMTD; logarithmic mean } \\
\text { temperature difference } \\
H ; \text { hot, } C \text {; cold }\end{array}$ \\
\hline$\dot{Q}_{i n}=\dot{m}_{w f}\left(h_{i}-h_{e}\right)$ & $\begin{array}{l}\dot{Q}_{i n} ; \text { heat transferred to } \\
\text { the working }\end{array}$ & $\dot{D}_{D, k}=c_{f, k} \dot{E} x_{D, k}$ & $\begin{array}{l}\dot{D}_{D, k} ; \text { exergy destruction } \\
\text { cost rate }\end{array}$ \\
\hline$\eta=\left(\frac{\text { energy in products }}{\text { total energy input }}\right)=\frac{\dot{W}_{\text {net }}}{\dot{Q}_{\text {in }}}$ & $\eta$; energy efficiency & $\begin{array}{l}\varepsilon=\left(\frac{\text { exergy in products }}{\text { total exergy input }}\right)=\frac{\dot{W}_{n e t}}{\dot{m}_{w f}\left(\psi_{i}-\psi_{e}\right)} \\
\dot{E} x_{F}-\dot{E} x_{P}=\dot{E} x_{D}\end{array}$ & $\begin{array}{l}\varepsilon ; \text { exergy efficiency } \\
\text { F; fuel, P; product, } \\
\text { D; destruction }\end{array}$ \\
\hline
\end{tabular}

\subsection{Thermodynamic and Thermoeconomic Relations}

The governing thermodynamic and thermoeconomic relations, including economic assumptions used in the FBSSI plant and TS-ORC system analyses, are presented in Table 3 [37-39]. The following assumptions are made for the thermodynamic analysis:

- All subsystems in the FBSSI plant and TS-ORC system operate in the steady-state conditions.

- The values for the reference environment (dead state) temperature and pressure are taken as $20^{\circ} \mathrm{C}$ and 1.0 bar, respectively.

- The combustion reaction in the FB combustor is complete.

- The kinetic and potential energy changes are negligible.

- The pressure losses taking place in the flows of working fluids through the pipes and heat exchangers are negligible.

- The exhaust gas is assumed as air. The exhaust gas and the air are assumed to be handled with sufficient accuracy by the ideal gas model at all states considered in the analysis.

- The heat exchangers' effectiveness is assumed as 0.85 , and the isentropic efficiencies of the turbines, compressors and pumps are 0.85 [37].

The Chemical engineering plant cost index (CEPCI) is an essential parameter calculated using the ratio between the cost index of the reference year and the current year and considered in the calculation of facility costs [37]. Correlations given for purchase cost are usually explained by a cost index that needs to be updated using the CEPCI factor. It is calculated by the ratio of the CEPCI values of the reference years. The reference years should be chosen as the commissioned date of the facility and the model design year [38]. In this study, the facility cost index is selected for the years 2012 and 2020 to make a reliable thermoeconomic analysis [40-42]. The reference year is chosen as the year 2012 when the FBSSI plant was commissioned. In this study, the CEPCI value is calculated as 0.901, and the components are updated according to this value.

\subsection{NSGA-II Optimization}

Evolutionary multi-objective optimization (EMO) is an established method for optimizing two or more objectives simultaneously. In this study, multi-objective optimization is performed in MATLAB using the non-dominated sorting genetic algorithm (NSGA-II) method. In this method, total production cost and exergy efficiency are determined as the TS-ORC system's objective functions. The main purpose of selecting these two objectives is that the current economic analysis is based on the exergy cost. In this way, the optimization result makes it possible to increase the system's efficiency and reduce the total cost by improving the design parameters. Decision variables determined to perform multiobjective optimization are given as

- $\quad$ pressure ratio (PR),

- the difference between the outlet temperature of the hot fluid and the inlet temperature of the cold fluid at each heat exchanger $\left(T_{x}\right)$

- $\quad$ and the dead state temperature $\left(T_{0}\right)$.

The population size, Pareto fraction, and the number of generations are 120, 0.8 and 1000, respectively. The flowchart of optimization in the TS-ORC system is shown in Figure. 2. The limits of the decision variables for optimization of objective functions are given in Table 4

Table 4. The limits of the decision parameters for the TSORC system

\begin{tabular}{ccc}
\hline Pressure ratio & $P R$ & $5 \leq P R \leq 15$ \\
Temperature difference & $T_{X}$ & $10 \leq T_{X} \leq 20$ \\
Dead state temperature & $T_{0}$ & $15 \leq T_{0} \leq 25$ \\
\hline
\end{tabular}

\section{Results and Discussion}

\subsection{Thermodynamic Analysis of FBSSI Plant}

Energy and exergy analyses of the GASKI FBSSI plant are performed using an educational version of Cycle-Tempo 


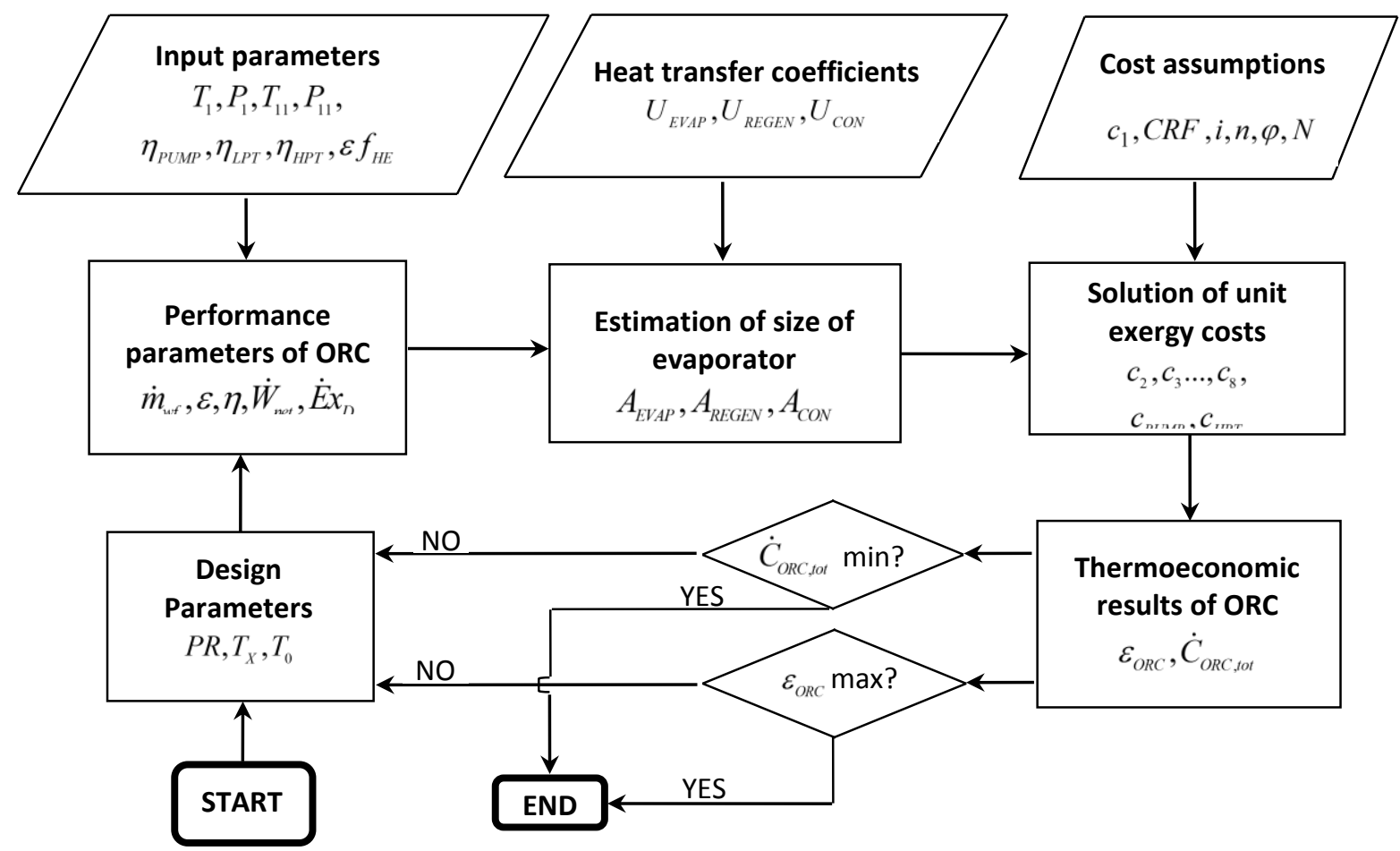

Figure 2. The flow chart for the optimization of the TS-ORC

software [43]. The temperature, pressure, and mass flow rate data and specific exergy values of the plant according to the nomenclature shown in Figure. 1 are presented in Table 5. Thermodynamic analysis results for the components of FBSSI plant is given in Table 6.

Table 5. Thermodynamic properties of the FBSSI plant with respect to state points in Figure.1

\begin{tabular}{cccccc}
\hline State & Fluid & $P($ bar $)$ & $T\left({ }^{\circ} \mathrm{C}\right)$ & $\dot{m}(\mathrm{~kg} / \mathrm{s})$ & $\Psi(\mathrm{kj} / \mathrm{kg})$ \\
\hline 1 & Exhaust & 1.013 & 280 & 5.268 & 76.78 \\
2 & Exhaust & 1.013 & 60 & 5.268 & 3.57 \\
11 & Exhaust & 1.077 & 196.3 & 4.460 & 45.15 \\
12 & Exhaust & 1.077 & 60 & 4.460 & 8.72 \\
13 & Sludge & 1.013 & 200.00 & 2.344 & 2942.09 \\
14 & Air & 1.100 & 24.00 & 3.549 & 7.09 \\
15 & Oil & 1.013 & 200.00 & 5.555 & 162.27 \\
16 & Oil & 1.013 & 240.00 & 5.555 & 192.52 \\
17 & Flue gas & 1.013 & 994.00 & 5.893 & 781.85 \\
18 & Air & 1.095 & 538.00 & 3.549 & 245.10 \\
19 & Air & 1.013 & 669.00 & 3.549 & 337.30 \\
20 & Flue gas & 1.013 & 876.00 & 5.893 & 659.69 \\
21 & Flue gas & 1.012 & 628.78 & 5.893 & 426.09 \\
22 & Flue gas & 1.010 & 442.00 & 5.893 & 275.64 \\
23 & Air & 1.013 & 24.00 & 5.268 & 0.25 \\
24 & Flue gas & 1.003 & 222.00 & 5.186 & 126.82 \\
25 & Flue gas & 1.003 & 186.00 & 4.460 & 111.00 \\
26 & Ash & 1.006 & 154.00 & 0.726 & 99.36 \\
27 & Ash & 1.041 & 158.56 & 0.726 & 104.00 \\
28 & Ash & 1.003 & 154.00 & 0.707 & 96.76 \\
29 & Ash & 1.041 & 158.56 & 0.707 & 101.27 \\
\hline
\end{tabular}

Following Szargut et al. [44], the specific chemical exergy of a technical fuel such as sewage sludge containing a small amount of ash may be adopted as $\psi_{\text {sludge }}^{\mathrm{CH}}=\left(L H V_{\text {sludge }}+\square_{\text {evap }} Z_{\text {water }}\right) \beta+\left(\psi_{\text {sulfur }}^{\mathrm{CH}}-\right.$ $\left.L H V_{\text {sulfur }}\right) z_{\text {sulfur }}+\psi_{\text {ash }}^{\mathrm{CH}} Z_{\text {ash }}+\psi_{\text {water }}^{\mathrm{CH}} Z_{\text {water }}$

where $L H V_{\text {sludge }}$ and $L H V_{\text {sulfur }}$ are the lower heating values of sludge and sulfur respectively; $h_{\text {evap }}$ is the enthalpy of water vaporization; $z_{\text {water }}, Z_{\text {sulfur }}, z_{\text {ash }}$ are the mass fractions of water, sulfur and ash respectively; $\psi_{\text {sulfur }}^{\mathrm{CH}}, \psi_{\mathrm{ash}}^{\mathrm{CH}}$, and $\psi_{\text {water }}^{\mathrm{CH}}$ are the specific chemical exergies of sulfur, ash, and water respectively. $\beta$ is a variable ratio which gives the atomic ratios in a mixture and does not depend on environmental parameters. It can be obtained for the sludge including the ratio of oxygen to carbon $(\mathrm{O} / \mathrm{C})$ less than 0.5 by the following relation:

$\beta_{\text {sludge }}=1.0437+0.0140 \frac{\mathrm{H}}{\mathrm{C}}+0.0968 \frac{\mathrm{O}}{\mathrm{C}}+0.0467 \frac{\mathrm{N}}{\mathrm{C}}$

where $H, C, O$ and $N$ are the percentage values of hydrogen, carbon, oxygen and nitrogen in the sludge, respectively. At the inlet of the FBSSI plant, the digested sewage sludge has a dry matter content of about $22 \%$ and its specific chemical

Table 6. Energy and exergy analysis results for the subsystems in the FBSSI plant.

\begin{tabular}{|c|c|c|c|c|c|c|}
\hline Component & $\dot{Q}(\mathrm{~kW})$ & $\dot{\boldsymbol{W}}(\mathrm{kW})$ & $\dot{\boldsymbol{E}} \boldsymbol{x}_{\boldsymbol{F}}(\mathrm{kW})$ & $\dot{\boldsymbol{E}} \boldsymbol{x}_{\boldsymbol{P}}(\mathrm{kW})$ & $\dot{\boldsymbol{E}} \boldsymbol{x}_{\boldsymbol{D}}(\mathrm{kW})$ & $\boldsymbol{\varepsilon}(\%)$ \\
\hline FB Combustor & $\begin{array}{c}-28,128 \\
+404.66 \\
+7466.43\end{array}$ & - & 8994.75 & 5676.89 & 3317.86 & 63.11 \\
\hline First Economizer & $\begin{array}{l}-695.00 \\
+467.00\end{array}$ & - & 719.89 & 327.22 & 392.67 & 45.46 \\
\hline Second Economizer & $\begin{array}{l}-1824.1 \\
+1457.0\end{array}$ & - & 1376.60 & 844.70 & 531.90 & 61.36 \\
\hline Third Economizer & $\begin{array}{l}-1346.00 \\
+1100.70\end{array}$ & - & 886.60 & 403.16 & 483.44 & 45.47 \\
\hline Cyclone & -1595.28 & - & 1520.00 & 726.41 & 793.60 & 47.79 \\
\hline Dust Filter & -241.20 & - & 657.70 & 567.20 & 90.50 & 86.24 \\
\hline Ash Tank Compressor & - & 13.76 & 13.76 & 10.48 & 3.28 & 76.16 \\
\hline Dust Tank Compressor & - & 14.15 & 14.15 & 10.78 & 3.37 & 76.18 \\
\hline Dust Filter Compressor & - & 205.71 & 205.71 & 158.17 & 47.54 & 76.89 \\
\hline FBSSI & $-28,128$ & - & 9021.30 & 6359.40 & 2661.90 & 70.50 \\
\hline
\end{tabular}


exergy becomes $2942.09 \mathrm{~kJ} / \mathrm{kg}$ based on the specific exergy value of the dry sludge (see Table 5), which is obtained as $13,373 \mathrm{~kJ} / \mathrm{kg}$ by Equation (1) and the data given in Table 7 [45]. The lower heating value (LHV) of the digested dry sludge is taken as $12,000 \mathrm{~kJ} / \mathrm{kg}$ [46].

Table 7. The digested sewage sludge composition [45]

\begin{tabular}{cc} 
Content & Volumetric values (\%) \\
\hline Carbon $(\mathrm{C})$ & 50.0 \\
Hydrogen $(\mathrm{H})$ & 2.5 \\
Oxygen $(\mathrm{O})$ & 12.5 \\
Nitrogen $(\mathrm{N})$ & 1.1 \\
Sulfur $(\mathrm{S})$ & 0.4 \\
Ash & 10.0 \\
Other & 23.5 \\
\hline
\end{tabular}

We note the followings from these results:

- The FB combustor has the highest exergy destruction at the FBSSI plant, with approximately $3317.86 \mathrm{~kW}$. The exergy efficiency of this component is found to be $63.11 \%$. The exergy destruction of the combustion process is mainly due to the irreversibilities associated with chemical reactions and heat transfer. Other causes of exergy destruction in the FB combustor are friction and mixing. Some of this destruction can be prevented by more effective preheating of the sludge and reducing the excess air. Note that the system for which thermodynamic analysis is made is a facility analyzed with real operating data. In this existing system, the exhaust gas transfers its heat to the air by entering a heat exchanger, and then heated air is blown onto the treatment sludge waiting in a sludge tank, unlike the scenario we developed by integrating the TS-ORC system. That is why sewage sludge enters the FB combustor at $200^{\circ} \mathrm{C}$ (see state 13 in Table 5). Figure. 1 does not show this preheating process of the sludge by blowing hot air in the plant. Because in the $\mathrm{WtE}$ scenario developed in this study, all exhaust gas rejected from FB combustor provides heat to the TS-ORC system to generate electricity. Thus, if it is desired to evaluate the waste heat of an existing sludge incineration plant integrated with an ORC system as suggested in this study, the design conditions of the preheating system of sewage sludge should be reviewed. As understood from the thermodynamic analysis results of the existing system, preheating of the sludge has a remarkable effect on increasing the combustion efficiency.

- The second highest exergy destruction in the FBSSI plant is taken place in the cyclone. This device is used to separate ashes from the flue gas. The cyclone has an exergy destruction amount of $794 \mathrm{~kW}$. While ash is separating from flue gas, heat transfer to the surroundings is always accompanied by exergy transfer.

- The third largest share of the total exergy destruction of the overall plant originates from the first economizer, which has the exergy destruction of about $532 \mathrm{~kW}$, and its exergy efficiency is found to be approximately $61 \%$. Exergy destruction in a heat exchanger is mostly caused by the temperature and mass flow rate differences between the material flow and phase difference. Exergy destruction in the first economizer is caused by the relatively high mean temperature difference of about $250^{\circ} \mathrm{C}$. As a result, the temperature difference of the fluids should be minimized to reduce exergy destruction. Two measures can achieve this: increase of the heat transfer area and decreased airflow. The other air preheaters, the second and third economizers have high amounts of exergy destructions in the FBSSI plant, and their exergy destructions are found to be 393 and $483.3 \mathrm{~kW}$, respectively. These destructions are mainly due to the relatively high-temperature differences of the fluids.

- Contrary to the components described above, the facility's product conditioning components play a minor role in exergy analysis. It is because they do not serve for energy conversion but for material separation. Exergy destruction in these components is mainly due to friction.

The exergy efficiency for the FBSSI plant can be calculated using the equation in the following (state numbers refer to Figure. 1 and Table 5),

$$
\begin{aligned}
& \varepsilon_{F B S S I}=\frac{\sum \dot{E} x_{P}}{\sum \dot{E} x_{F}} \\
& =\frac{\dot{E} x_{1}+\dot{E} x_{11}+\dot{E} x_{16}+\dot{E} x_{17}+\dot{E} x_{29}}{\dot{E} x_{13}^{C \square \text { emical }}+\dot{E} x_{14}+\dot{E} x_{15}+\dot{E} x_{19}+\dot{E} x_{23}}
\end{aligned}
$$

Using Equation (3), the exergy efficiency of the facility is found to be $70.5 \%$ which proves that exergy transfer by heat is inevitably degraded mostly due to the hightemperature differences between systems' boundary and the environment. It is possible to increase the exergy efficiency of the existing FBSSI facility by using the waste heat source (exhaust gas) in the system more efficiently by developing a TS-ORC scenario to be integrated into the FBSSI facility.

\subsection{Thermodynamic and Thermoeconomic Analyses of TS-ORC}

In this study, considering three working fluids listed in Table 2, detailed thermodynamic and thermoeconomic analyses of the TS-ORC system are performed comparatively using the governing equations given in Table 3 . The thermodynamic and thermoeconomic analyses results obtained are presented in Table 9 using the design parameters listed in Table 1 and the thermodynamic properties given in Table 8 .

The thermodynamic and thermoeconomic analysis results of the TS-ORC system using the working fluids listed in Table 2 are shown in Table 10. The analysis results listed in Table 10 can be evaluated as follows:

- The highest power generation in the TS-ORC system $(183.40 \mathrm{~kW})$ is achieved using R1234yf as working fluid. However, considering the economic viability, which is one of the most important issues to be taken into account for all engineering systems, it is seen that $\mathrm{R} 1234 \mathrm{yf}$ is also the most expensive fluid for electricity generation among the fluids listed in Table 10 (10.57 $\$ / h)$.

- On the other hand, the least electricity generation $(142.70 \mathrm{~kW})$ occurs at the thermoeconomically most affordable cost with R245fa $(9.35 \$ / \mathrm{h})$. It is clearly seen that there is an inverse proportion between thermodynamic and thermoeconomic performances of the working fluids. Considering the governing equations given in Table 3 used to obtain the sub-components PEC values in each designed TS-ORC system based on the type of working fluid, the reason for this inverse ratio becomes apparent. Since the system's equipment costs with high power generation increase, then the power 
Table 8. Thermodynamic properties of the TS-ORC with respect to state points in Figure.1

\begin{tabular}{|c|c|c|c|c|c|c|c|c|}
\hline \multirow{13}{*}{$\begin{array}{l}\frac{\pi}{\sqrt[\pi]{n}} \\
\stackrel{5}{\sim}\end{array}$} & State & Fluid & $T\left({ }^{\circ} \mathrm{C}\right)$ & $P$ (bar) & $\dot{m}(\mathrm{~kg} / \mathrm{s})$ & $h(\mathrm{~kJ} / \mathrm{kg})$ & $s(\mathrm{~kJ} / \mathrm{kg} . \mathrm{K})$ & $\Psi(\mathrm{kJ} / \mathrm{kg})$ \\
\hline & 1 & Exhaust & 280 & 1.013 & 5.268 & 558.3 & 6.323 & 76.78 \\
\hline & 2 & Exhaust & 60 & 1.013 & 5.268 & 333.8 & 5.807 & 3.567 \\
\hline & 3 & $\mathrm{R} 245 \mathrm{fa}$ & 45 & 26.46 & 3.364 & 259.9 & 1.196 & 6.746 \\
\hline & 4 & $\mathrm{R} 245 \mathrm{fa}$ & 181.3 & 26.46 & 3.364 & 558.7 & 1.961 & 81.5 \\
\hline & 5 & $\mathrm{R} 245 \mathrm{fa}$ & 134.5 & 5.291 & 3.364 & 527.2 & 1.974 & 45.9 \\
\hline & 6 & $\mathrm{R} 245 \mathrm{fa}$ & 181.3 & 5.291 & 3.364 & 579.7 & 2.096 & 62.7 \\
\hline & 7 & $\mathrm{R} 245 \mathrm{fa}$ & 165.4 & 2.646 & 3.364 & 564 & 2.103 & 45.05 \\
\hline & 8 & $\mathrm{R} 245 \mathrm{fa}$ & 41.78 & 2.646 & 3.364 & 255 & 1.187 & 4.674 \\
\hline & 9 & Water & 20 & 1 & 9.602 & 83.93 & 0.2962 & 0 \\
\hline & 10 & Water & 42 & 1 & 9.602 & 175.9 & 0.5989 & 3.289 \\
\hline & 11 & Exhaust & 196.3 & 1.077 & 4.46 & 472 & 6.137 & 45.15 \\
\hline & 12 & Exhaust & 60 & 1.077 & 4.46 & 333.8 & 5.79 & 8.722 \\
\hline \multirow{12}{*}{$\begin{array}{l}\stackrel{\mathbb{N}}{\mathcal{N}} \\
\stackrel{N}{\simeq}\end{array}$} & 1 & Exhaust & 280 & 1.013 & 5.268 & 558.3 & 6.323 & 76.78 \\
\hline & 2 & Exhaust & 60 & 1.013 & 5.268 & 333.8 & 5.807 & 3.567 \\
\hline & 3 & R1234ze & 45 & 80.48 & 4.282 & 263.1 & 1.192 & 37.01 \\
\hline & 4 & R1234ze & 181.3 & 80.48 & 4.282 & 497.9 & 1.798 & 94.05 \\
\hline & 5 & R1234ze & 106.5 & 16.1 & 4.282 & 470.1 & 1.811 & 62.49 \\
\hline & 6 & R1234ze & 181.3 & 16.1 & 4.282 & 556.1 & 2.017 & 87.85 \\
\hline & 7 & R1234ze & 160.3 & 8.048 & 4.282 & 538.4 & 2.025 & 68.03 \\
\hline & 8 & R1234ze & 41.78 & 8.048 & 4.282 & 258.3 & 1.197 & 30.68 \\
\hline & 9 & Water & 20 & 1 & 11.08 & 83.93 & 0.2962 & 0 \\
\hline & 10 & Water & 42 & 1 & 11.08 & 175.9 & 0.5989 & 3.289 \\
\hline & 11 & Exhaust & 196.3 & 1.077 & 4.46 & 472 & 6.137 & 45.15 \\
\hline & 12 & Exhaust & 60 & 1.077 & 4.46 & 333.8 & 5.79 & 8.722 \\
\hline \multirow{12}{*}{ 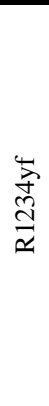 } & 1 & Exhaust & 280 & 1.013 & 5.268 & 558.3 & 6.323 & 76.78 \\
\hline & 2 & Exhaust & 60 & 1.013 & 5.268 & 333.8 & 5.807 & 3.567 \\
\hline & 3 & R1234yf & 45 & 106.5 & 4.701 & 261 & 1.178 & 45.08 \\
\hline & 4 & R1234yf & 181.3 & 106.5 & 4.701 & 474.9 & 1.731 & 96.66 \\
\hline & 5 & R1234yf & 107.5 & 21.3 & 4.701 & 448.6 & 1.743 & 66.79 \\
\hline & 6 & R1234yf & 181.3 & 21.3 & 4.701 & 538.6 & 1.959 & 93.42 \\
\hline & 7 & R1234yf & 160.3 & 10.65 & 4.701 & 521.2 & 1.967 & 73.94 \\
\hline & 8 & R1234yf & 41.78 & 10.65 & 4.701 & 256.4 & 1.191 & 36.33 \\
\hline & 9 & Water & 20 & 1 & 11.5 & 83.93 & 0.2962 & 0 \\
\hline & 10 & Water & 42 & 1 & 11.5 & 175.9 & 0.5989 & 3.289 \\
\hline & 11 & Exhaust & 196.3 & 1.077 & 4.46 & 472 & 6.137 & 45.15 \\
\hline & 12 & Exhaust & 60 & 1.077 & 4.46 & 333.8 & 5.79 & 8.722 \\
\hline
\end{tabular}

Table 9. Exergy and cost flow rates of the TS-ORC with respect to state points in Figure.1

\begin{tabular}{|c|c|c|c|c|c|c|}
\hline \multirow{2}{*}{ State } & \multicolumn{2}{|c|}{ R245fa } & \multicolumn{2}{|c|}{ R1234ze } & \multicolumn{2}{|c|}{ R1234yf } \\
\hline & $\dot{E} x(\mathrm{~kW})$ & $\dot{C}(\$ / \mathrm{h})$ & $\dot{E} x(\mathrm{~kW})$ & $\dot{C}(\$ / \mathrm{h})$ & $\dot{E} x(\mathrm{~kW})$ & $\dot{C}(\$ / \mathrm{h})$ \\
\hline 1 & 404.48 & 1.456 & 404.48 & 1.456 & 404.48 & 1.456 \\
\hline 2 & 18.79 & 0.06764 & 18.79 & 0.06764 & 18.79 & 0.06764 \\
\hline 3 & 22.69 & 2.85 & 158.48 & 1.567 & 211.92 & 1.481 \\
\hline 4 & 274.17 & 5.442 & 402.72 & 4.16 & 454.40 & 4.087 \\
\hline 5 & 154.41 & 3.065 & 267.58 & 2.764 & 313.98 & 2.815 \\
\hline 6 & 210.92 & 4.187 & 376.17 & 3.886 & 439.17 & 3.937 \\
\hline 7 & 151.55 & 3.408 & 291.30 & 3.349 & 347.59 & 3.447 \\
\hline 8 & 15.72 & 1.339 & 131.37 & 0.03134 & 170.79 & 0.1561 \\
\hline 9 & 0.00 & 0 & 0.00 & 0 & 0.00 & 0 \\
\hline 10 & 31.58 & 2.204 & 36.44 & 3.551 & 37.82 & 3.791 \\
\hline 11 & 201.37 & 0.7249 & 201.37 & 0.7249 & 201.37 & 0.7249 \\
\hline 12 & 38.90 & 0.14 & 38.90 & 0.14 & 38.90 & 0.14 \\
\hline
\end{tabular}

production cost is expected to increase. For this reason, it is revealed that optimization is critical to find the most suitable conditions for a system.

- In the assessment of the WtE systems, the cost associated with the thermodynamically optimal cases are sometimes significantly higher. Accordingly, studies focusing only on the thermodynamically optimal performance to improve an existing system can lead to gross misevaluations and skewed decision making. On the other hand, qualitative analysis of energy, which is the basis of a rational cost assessment, offers a realistic perspective in improving systems. In the following section, the proposed system scenario's performative optimization steps with an optimization strategy based on effective exergetic cost analysis are presented.

The overall exergy efficiency for the FBSSI+TS-ORC system can be calculated using the equation in the following (state numbers refer to Figure. 1 and Tables 5 and 10),

$$
\begin{aligned}
& \varepsilon_{F B S S I+T S-O R C}=\frac{\sum \dot{E} x_{P}}{\sum \dot{E} x_{F}} \\
& =\frac{\dot{E} x_{16}+\dot{E} x_{17}+\dot{E} x_{29}+\dot{W}_{n e t, T S-O R C}}{\dot{E} x_{13}^{C \square \text { emical }}+\dot{E} x_{19}}
\end{aligned}
$$

Table 10. Thermodynamic and thermoeconomic analysis results of the TS-ORC

\begin{tabular}{cccccc}
\hline $\begin{array}{c}\text { Working } \\
\text { fluid }\end{array}$ & $\begin{array}{c}\eta \\
(\%)\end{array}$ & $\begin{array}{c}\varepsilon \\
(\%)\end{array}$ & $\begin{array}{c}\dot{\mathrm{W}} \\
(\mathrm{kW})\end{array}$ & $\begin{array}{c}\dot{\mathrm{CORC}} \\
(\$ / \mathrm{h})\end{array}$ & $\begin{array}{c}\dot{\mathrm{Z} O R C, t o t} \\
(\$ / \mathrm{h})\end{array}$ \\
\hline R245fa & 2.83 & 23.55 & 142.70 & 9.35 & 7.38 \\
R1234ze & 3.45 & 28.70 & 173.90 & 10.29 & 8.32 \\
R1234yf & 3.63 & 30.30 & 183.40 & 10.57 & 8.59 \\
\hline
\end{tabular}

The FBSSI + TS-ORC system's overall exergy efficiencies are found to be $72.8 \%, 73.2 \%$, and $73.3 \%$ using Equation (4) for the selected working fluids R245fa, R1234ze, R1234yf, respectively. It is observed that the contribution of the TS-ORC system to an effective exergy 


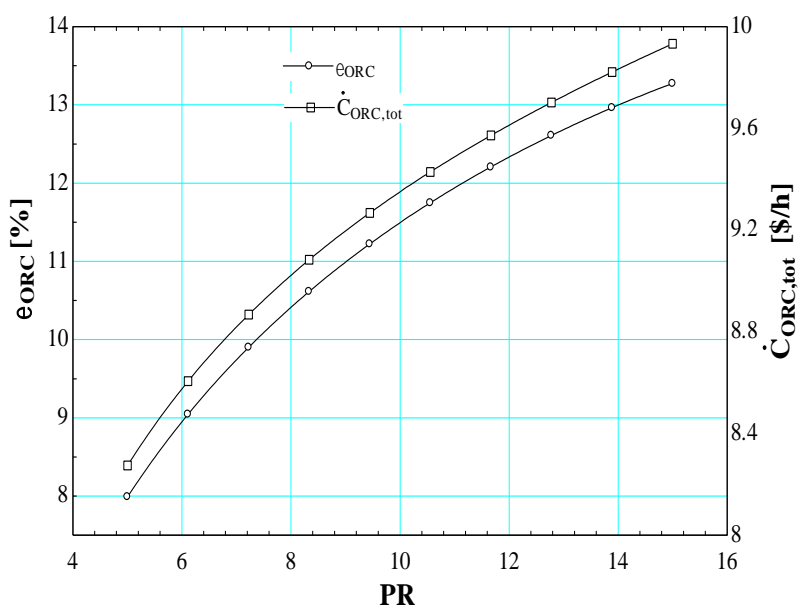

(a)

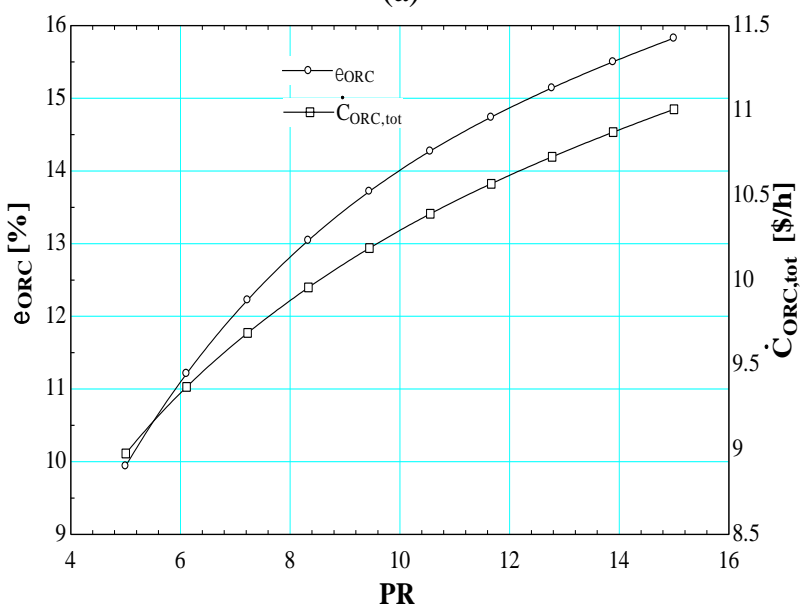

(b)

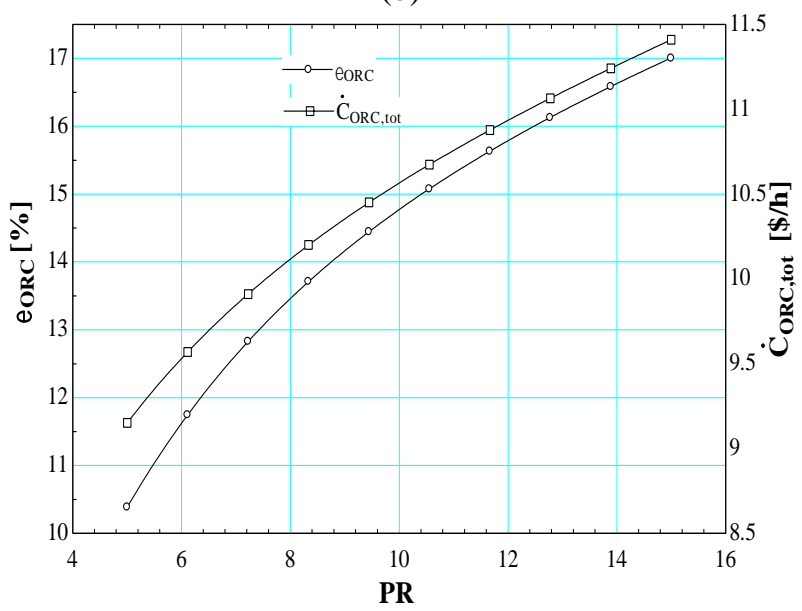

(c)

Figure 3. The effect of the pressure ratio $(P R)$ on the exergy efficiency and total exergetic cost rate of the TS-ORC for $(a)$ R245fa, (b) R1234ze, (c) R1234yf

usage of the waste heat discharged by exhaust gases at states 1 and 11 (see Figure. 1) is relatively low than expected. One reason for that we have to use a low-to-medium temperature heat source for the designed TS-ORC. The exhaust gas temperature gradually decreases off through the drying applications and auxiliary processes in the FBSSI plant. Correspondingly, the exergy of the combustion gases is mostly destructed through these mandatory processes in the FBSSI plant. This is the inevitable result since the main purpose of incineration in the FBSSI plant is to dry the sewage sludge by increasing its dry matter content to 50$60 \%$. As a final solution, developing an ORC system scenario in the scope of $\mathrm{WtE}$ for this case study may be seen as an economically not so feasible attempt with little benefit and high investment. However, if we consider the current global energy and environmental problems as our bottlenecks, we should not hesitate to offer innovative approaches to evaluate even the lowest heat source. Another solution can be district heating implication, and this will be taken into consideration in another research study; that is why the district heating scenario is excluded in this presented paper.

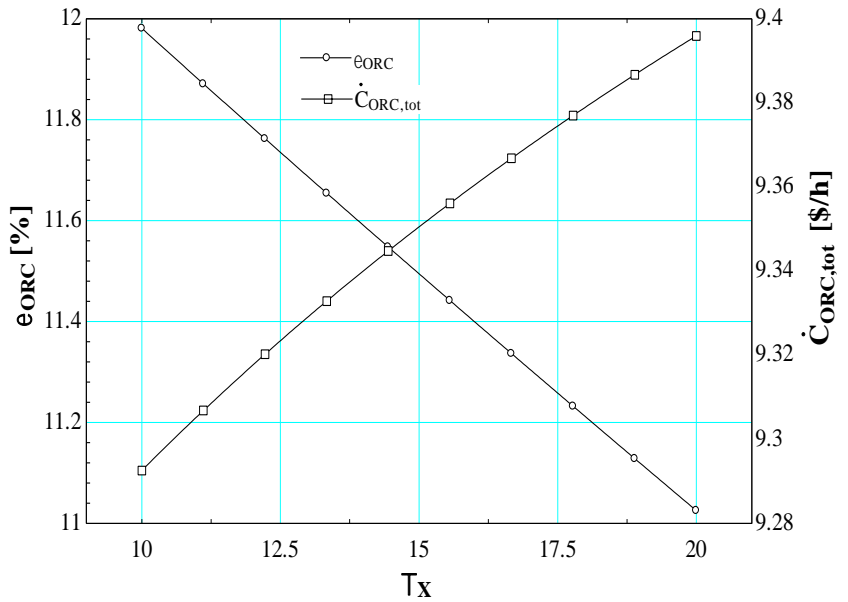

(a)

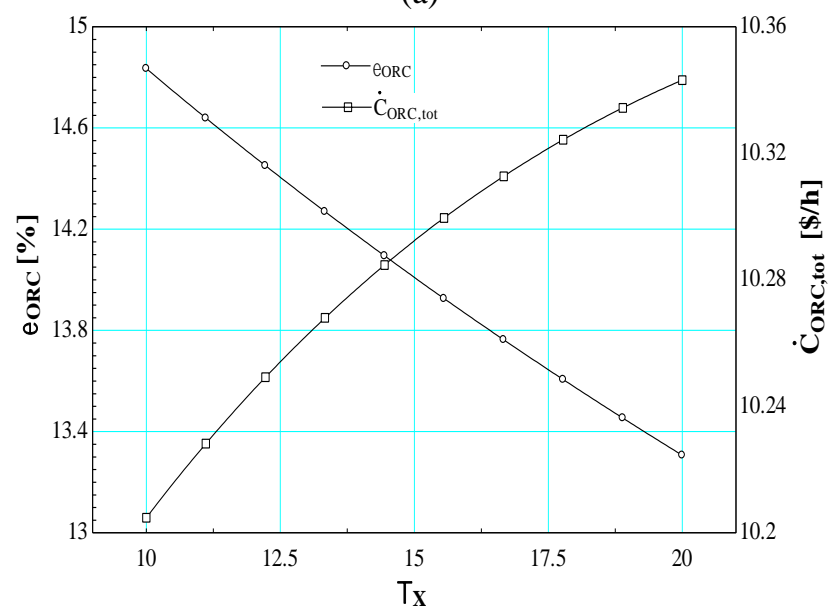

(b)

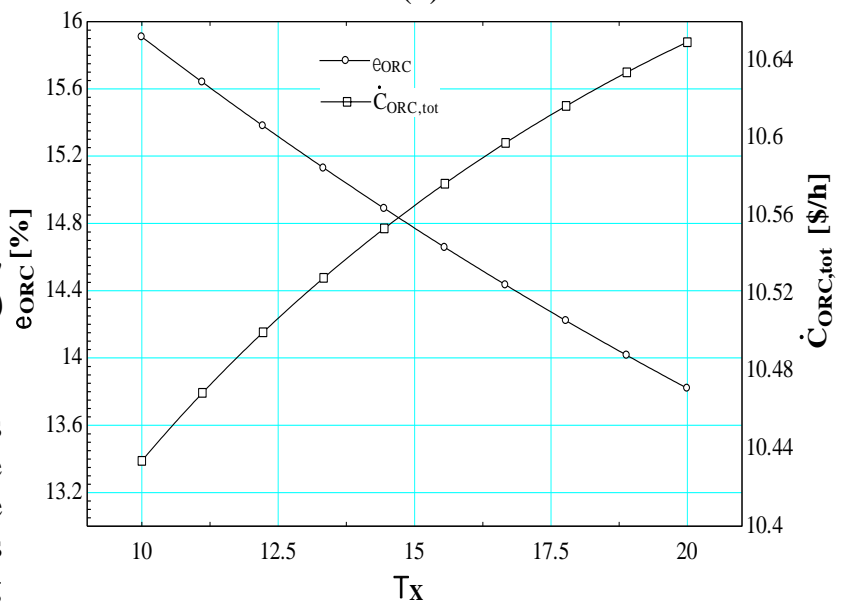

(c)

Figure 4. The effect of the temperature difference between the hot stream exit temperature and the cold stream inlet temperature in heat exchangers (Tx) on the exergy efficiency and total exergetic cost rate of the TS-ORC for (a) R245fa, (b) R1234ze, (c) R1234yf. 


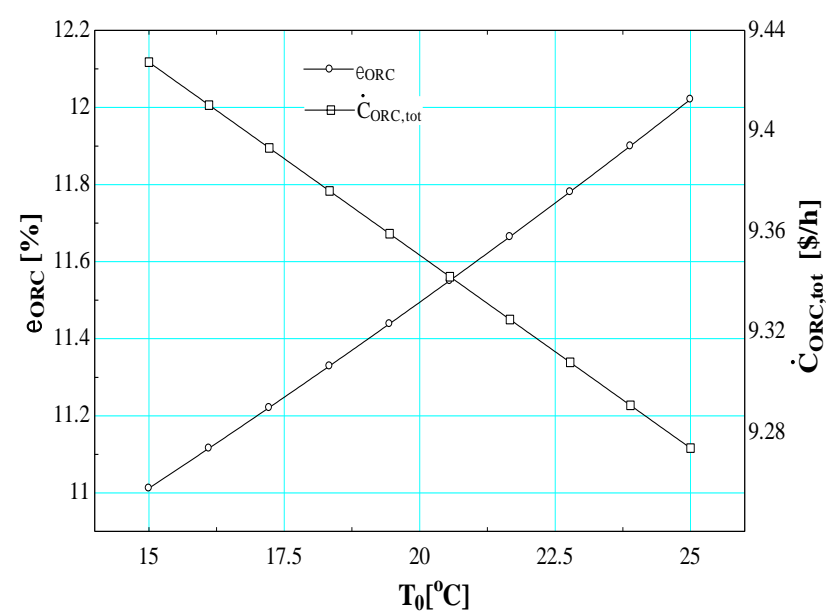

(a)

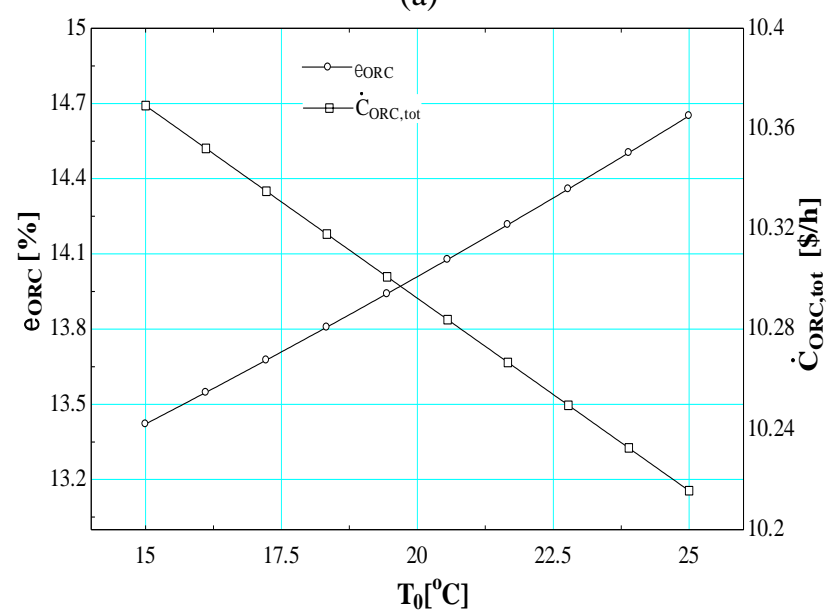

(b)

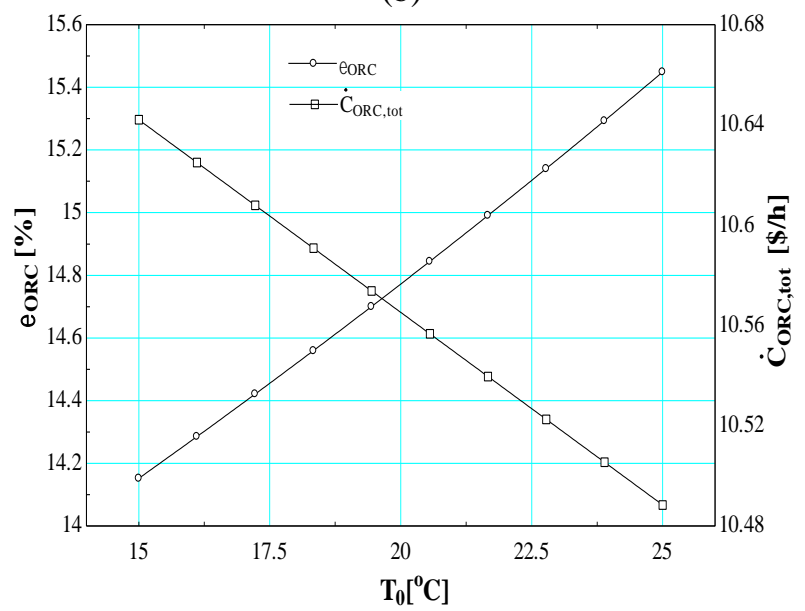

(c)

Figure 5. The effect of the dead state temperature (TO) on the exergy efficiency and total exergetic cost rate of the TS-ORC for (a) R245fa, (b) R1234ze, (c) R1234yf

In this study, various parametric studies are carried out using selected decision variables (PR, $T_{x}$, and $T_{0}$; see section 2.4) to evaluate the thermodynamic and thermoeconomic performances of the TS-ORC system. These parametric studies reveal the effects of the decision parameters' variations on the exergy efficiency and electricity production cost of the system. Figure. 3 shows the effect of the pressure ratio $(\mathrm{PR})$ on the exergy efficiency and total exergetic cost rate of the TS-ORC for each working fluid. As seen, both the exergy efficiency and total exergetic cost rate increase with increasing the pressure ratio of the TS-ORC system for each working fluid. As the pressure ratio increases, the working fluid at a higher pressure enters the turbines and leaves at a lower pressure. Thus, the net power output and exergy efficiency of the system increase. On the other hand, as the costs of the power production and consumption units of the system will increase with the increasing power generation, it is expected that the total production cost will also increase.

Figure. 4 shows the effect of the difference between the hot fluid's outlet temperature and cold fluid's inlet temperature of a heat exchanger on the system's exergy efficiency and total production cost. As understood, the increase in the temperature difference has a negative effect on both the exergy efficiency and total production cost of the TS-ORC system. Considering the TS-ORC system's design, the increase in temperature difference in the heat exchanger directly causes a decrease in the working fluid temperature at the turbine inlet. As a result, power generation in the turbine decreases, and power consumption in the pump increases due to the increasing load. This directly causes the reduction of the exergy efficiency of the TS-ORC. The total production cost can be expected to decrease considering the lower equipment costs due to reduced power generation. In this case, the costs required for both high-pressure and lowpressure turbines (PEC) are reduced. However, as the pump cost increases more than the cost of both turbines, the total production cost also increases. Thus, as the temperature difference $\left(T_{x}\right)$ increases in the heat exchanger, the TS-ORC system's exergy efficiency decreases, whereas the total production cost of the system increases.

Figure. 5 shows the effect of the dead state temperature on the exergy efficiency and total production cost of the TSORC for each working fluid. It is observed in Figure 5 that the increase in the dead-state temperature has a positive effect on both the exergy efficiency and total production cost. This is because exergy losses are reduced with the increasing environmental temperature while the net power generation in the system remains constant. Thus, while the exergy efficiency increases, the total production cost decreases with the increasing dead state temperature. Considering Figures 3 through 5 on the whole, it is seen that the most effective parameter in the TS-ORC system is the pressure ratio. As the pressure ratio changes, inlet and outlet pressures of the turbine change, and thus the net power output value changes accordingly. Seeing Figure.3, the exergy efficiency and total production cost change in percentage are more than Figures 4 and 5. However, a change at the same rate is not observed in the temperature difference or the dead state temperature change. This result reveals that pressure is a relatively more effective parameter in the TS-ORC design than temperature.

\section{Thermodynamic and Thermoeconomic Optimization of the TS-ORC}

In this study, each working fluid's Pareto frontier is created by using a multi-objective function solution according to both the best exergy efficiency and electricity generation cost. Note that each optimization solution evaluated can be considered as the best solution according to the decision stage. However, in this study, the most compromise solution is considered and emphasized as the best solution to compare the optimization and decision stage results. In making this choice, the results of the solutions obtained during the design phase are considered. Pareto frontier images corresponding to each working fluid are given in Figures 6 to 8. Exergy efficiency and total production cost values calculated at the TS-ORC system's design stage are determined as constraints and indicated with dashed lines on the Figures. In the Pareto frontier, the closest 
value of the optimum results between these dashed lines to the intersection is determined as "the best solution." Then, the decision parameters (PR, $T_{x}, T_{0}$ ) of this point are determined, and the optimum exergy efficiency and total production cost values of the TS-ORC system are calculated.

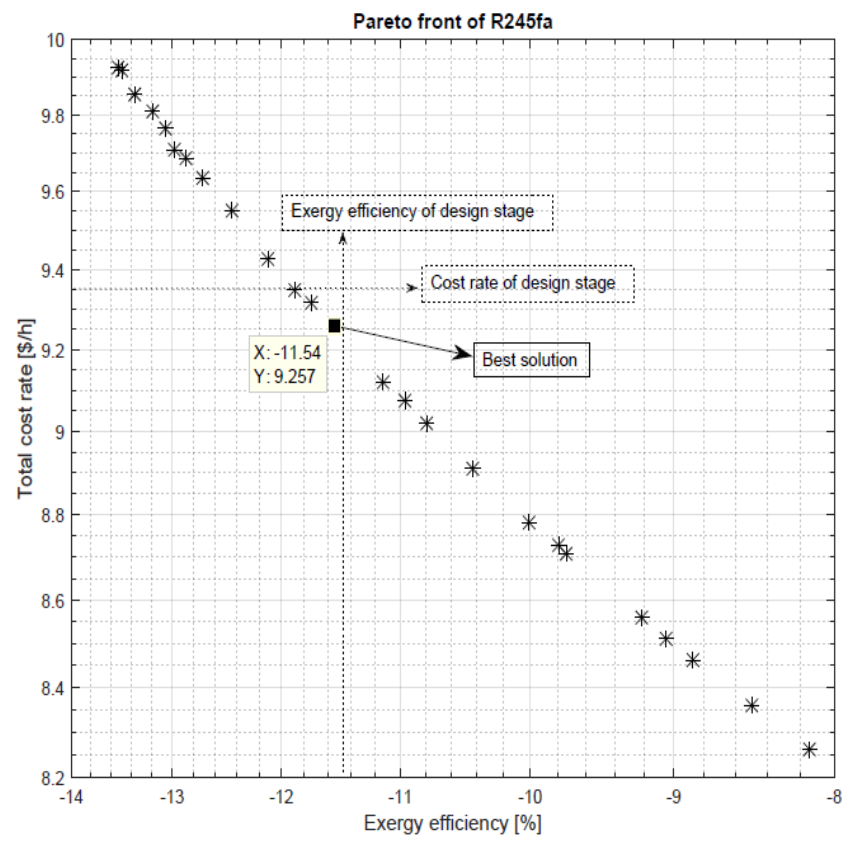

Figure 6. Pareto frontier of the R245fa in the TS-ORC

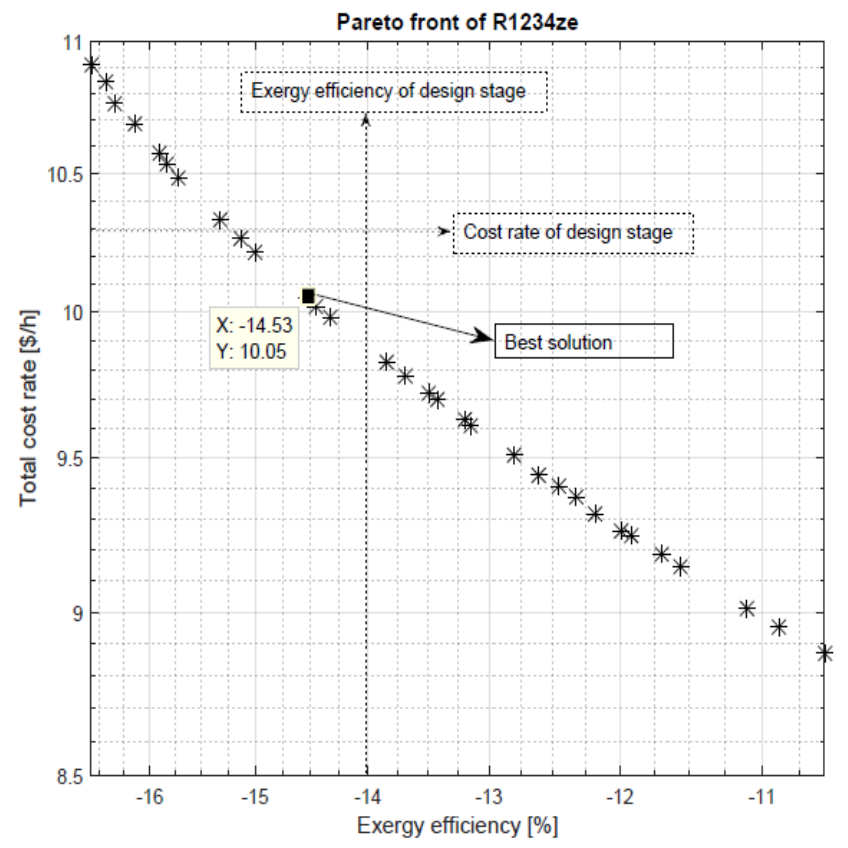

Figure 7. Pareto frontier of the R1234ze in the TS-ORC

Optimum design values depending on the decision parameters of each working fluid are shown in Table 11. These values are found with NSGA-II optimization. The variations in the optimum design values are determined during the design stages. The results determining the thermodynamic and thermoeconomic performance parameters of the TS-ORC system using each decision variable's optimum results are shown in Table 12. As seen, improvements are made for each fluid, and both thermodynamic and thermoeconomic performance improvements are observed. According to these results, the most suitable working fluid for the designed TS-ORC system cannot be indicated. Because as the power generation increases according to the working fluid selected, the system's total cost increases due to the increased equipment cost. Thus, it is necessary to consider more than one factor to make a suitable working fluid proposition for the TS-ORC system. Herein, the investor's budget plays a major role in choosing the working fluid. The electricity demand to be met by the designed TS-ORC system is relatively secondary since it is related to the investor's budget. As a result of the optimization, the highest increase in thermodynamic performance is achieved using R1234yf with a net power increase of 5\%. On the other hand, if the R1234ze is selected, a decrease of about $\% 2.8$ will be observed in the total production cost of the TS-ORC system.

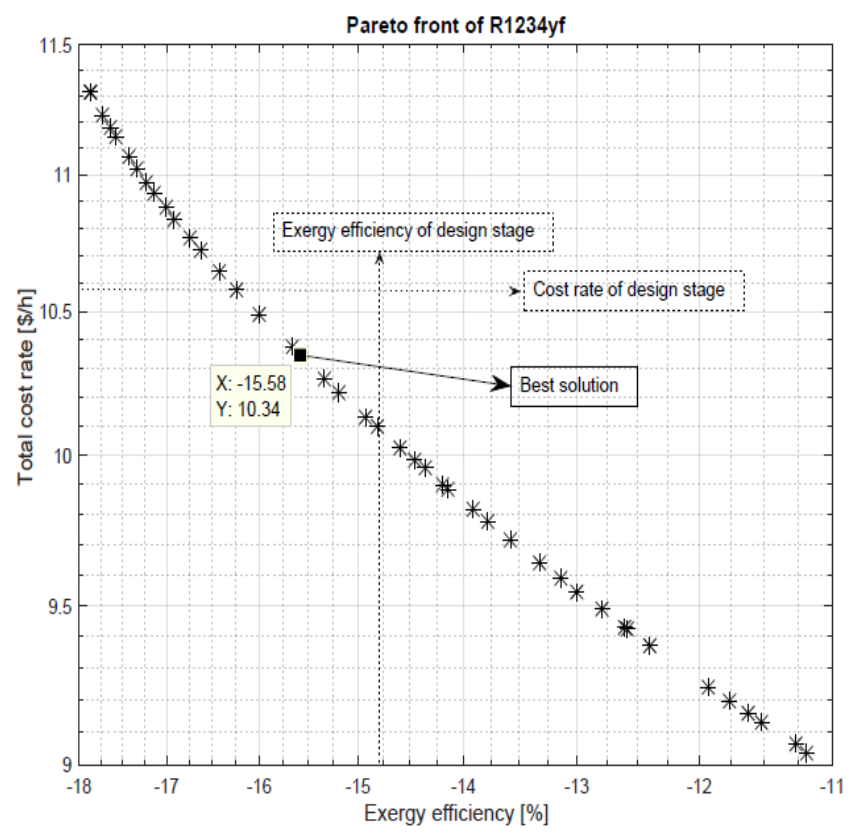

Figure 8. Pareto frontier of the R1234yf in the TS-ORC

Table 11. Optimum design values depending on the decision parameters for each working fluid using NSGA-II

\begin{tabular}{|c|c|c|c|c|}
\hline \multirow{2}{*}{$\begin{array}{c}\text { Decision } \\
\text { parameters }\end{array}$} & \multirow{2}{*}{$\begin{array}{l}\text { Decision } \\
\text { stage }\end{array}$} & \multicolumn{3}{|c|}{$\begin{array}{l}\text { Optimum design of decision parameters } \\
\text { for working fluids }\end{array}$} \\
\hline & & R245fa & R1234ze & R1234yf \\
\hline$P R$ & 10 & 9.55 & 9.26 & 9.52 \\
\hline$T_{x}$ & 15 & 10.71 & 10.11 & 10.37 \\
\hline$T_{0}$ & 20 & 18.46 & 20.98 & 20.50 \\
\hline
\end{tabular}

Table 12. NSGA-II results for the TS-ORC

\begin{tabular}{ccccccc}
\hline Performance & \multicolumn{2}{c}{ R245fa } & \multicolumn{2}{c}{ R1234ze } & \multicolumn{2}{c}{ R1234yf } \\
\cline { 2 - 7 } parameters & Design & NSGA & Design & NSGA & Design & NSGA \\
\hline$\dot{W}(\mathrm{~kW})$ & 142.70 & 145.20 & 173.90 & 178.80 & 183.40 & 192.60 \\
$\eta(\%)$ & 7.93 & 8.07 & 9.67 & 9.94 & 10.19 & 10.71 \\
$\varepsilon(\%)$ & 11.49 & 11.54 & 14.01 & 14.53 & 14.77 & 15.58 \\
$\dot{C}_{\text {ORC,tot }}$ & 9.35 & 9.26 & 10.29 & 10.05 & 10.57 & 10.34 \\
$(\$ / \mathrm{h})$ & & & & & & \\
$\dot{Z}_{\text {ORC,tot }}$ & 7.38 & 7.26 & 8.32 & 8.09 & 8.59 & 8.37 \\
$(\$ / \mathrm{h})$ & & & & & &
\end{tabular}

The decision-makers responsible for waste management in local municipalities should keep in mind that the exhaust gas sourced from the FBSSI facility is a unique and sustainable energy source in terms of waste-to-energy. Therefore, in a sewage sludge incineration facility, power generation should be envisaged depending on the incinerator's waste heat capacity rather than meeting a predetermined electricity requirement. Once this system is designed, it is necessary to ensure that the TS-ORC system operates under thermodynamically and thermoeconomically best circumstances. In this study, a systematic 
method is proposed and developed, and applied to provide the designed system's optimum working conditions. The use of sewage sludge as a sustainable resource within the scope of waste-to-energy can be encouraged by local governments to implement the study results.

According to the data received from TUIK [47], by the end of 2019, approximately 300,000 tons of municipal sewage sludge were produced in Turkey and the corresponding dry matter content of it was reported as nearly 60,000 tons. However, only $31.4 \%$ of the digested sewage sludge is being burned in FBSSI systems for disposal purposes. As seen, it is imperative that treatment sludge be disposed of in a sustainable manner by minimizing the damage to the environment. This study reveals the possibilities of a sustainable WtE approach for an effective design.

\section{Conclusion}

In this paper, a TS-ORC system is designed using the waste heat (exhaust gas) of a real FBSSI plant as a source. The TS-ORC design is built by the actual operating conditions of the FBSSI facility. Thermodynamic and thermoeconomic procedures and formulations are developed and expanded, considering the characteristics and structures of both the FBSSI plant and the designed TS-ORC system. TS-ORC system is analyzed and evaluated both thermodynamically and thermoeconomically according to the effects of three different working fluids on the performance parameters. Finally, the TS-ORC system's multi-objective optimization is performed in MATLAB using the non-dominated sorting genetic algorithm (NSGAII) method. In the following some concluding remarks are given:

- The FB combustor's exergy efficiency is $63.11 \%$, which corresponds to the exergy destruction of approximately $3317.86 \mathrm{~kW}$. The second highest exergy destruction in the FBSSI plant is taken place in the cyclone as $794 \mathrm{~kW}$. The third-largest share of the total exergy destruction of the overall FBSSI plant originates from the first economizer, which has the exergy destruction of about $532 \mathrm{~kW}$, and its exergy efficiency is found to be approximately $61 \%$. The second and third economizers have high amounts of exergy destructions in the FBSSI plant, and their exergy destructions are found to be 393 and $483.3 \mathrm{~kW}$, respectively. The exergy efficiency of the FBSSI plant is found to be $70.5 \%$ which proves that exergy transfer by heat is inevitably degraded mostly due to the high-temperature differences between systems' boundary and the environment.

- The highest power generation in the TS-ORC system $(183.40 \mathrm{~kW})$ is achieved using R1234yf as working fluid. R1234yf is also the most expensive fluid for electricity generation among the other working fluids (10.57 \$/h).

- The least electricity generation in the TS-ORC (142.70 $\mathrm{kW}$ ) occurs at the thermoeconomically most affordable cost with R245fa $(9.35 \$ / \mathrm{h})$.

- The FBSSI + TS-ORC system's overall exergy efficiencies are found to be $72.8 \%, 73.2 \%$, and $73.3 \%$ for the selected working fluids R245fa, R1234ze, R1234yf, respectively.

- Both the exergy efficiency and total exergetic cost rate increase with increasing the PR of the TS-ORC system for each working fluid.

- As the temperature difference $\left(T_{x}\right)$ increases in the heat exchanger, the TS-ORC system's exergy efficiency decreases, whereas the total production cost of the system increases.

- The increase in the dead-state temperature has a positive effect on both the exergy efficiency and total production cost. Thus, while the exergy efficiency increases, the total production cost decreases with the increasing dead state temperature.

- According to the optimization results, the most suitable working fluid for the designed TS-ORC system cannot be indicated. Because as the power generation increases according to the working fluid selected, the system's total cost increases due to the increased equipment cost. Thus, it is necessary to consider more than one factor to make a suitable working fluid proposition for the TSORC system, such as investor's budget, the electricity demand, etc.

\section{Acknowledgement}

The authors acknowledge the support of the "HeatReFlex-Green and Flexible District Heating/Cooling" project (www.heatreflex.et.aau.dk) funded by the Danida Fellowship Centre and the Ministry of Foreign Affairs of Denmark to research in growth and transition countries under the grant no. 18-M06-AAU.

$\begin{array}{ll}\text { Nomenclature } & \\ A & \text { heat transfer area, } \mathrm{m}^{2} \\ \dot{C} & \text { cost rate, } \$ / \mathrm{h} \\ c & \text { cost per exergy unit, } \$ / \mathrm{GJ} \\ c_{f} & \text { unit exergy cost of fuel, } \$ / \mathrm{GJ} \\ c_{p} & \text { unit exergy cost of fuel, } \$ / \mathrm{GJ} \\ \dot{D} & \text { cost rate of exergy destruction, } \$ / \mathrm{h} \\ \dot{E} x & \text { exergy rate, } \mathrm{kW} \\ \square & \text { specific enthalpy, } \mathrm{kJ} / \mathrm{kg} \\ i & \text { interest rate } \\ \dot{m} & \text { mass flow rate, } \mathrm{kg} / \mathrm{s} \\ n & \text { total life time } \\ N & \text { annual operation time } \\ P & \text { pressure, bar } \\ P R & \text { pressure ratio of TS-ORC } \\ \dot{Q} & \text { heat addition, } \mathrm{kW} \\ S & \text { specific entropy, } \mathrm{kJ} / \mathrm{kg}-\mathrm{K} \\ T & \text { temperature, }{ }^{\circ} \mathrm{C} \\ U & \text { heat transfer coefficient, } \mathrm{kW} / \mathrm{m}^{2}-\mathrm{K} \\ \dot{W} & \text { work flow rate-power, } \mathrm{kW} \\ \dot{Z} & \text { capital cost rate, } \$ / \mathrm{h} \\ & \end{array}$

Subscripts and Abbreviations

$0 \quad$ dead state

a actual

CEPCI chemical engineering plant cost index

CON condenser

CRF capital recovery factor

crit critical point

D destruction

EMO evolutionary multi-objective optimization

EVAP evaporator

exh exhaust

FBSSI fluidized bed sewage sludge incineration

HPT high-pressure turbine

ORC organic Rankine cycle

OT ORC turbine

$\mathrm{k}$ component 


$\begin{array}{ll}\text { LMTD } & \text { logarithmic mean temperature difference } \\ \text { LPT } & \text { low-pressure turbine } \\ \text { NSGA-II } & \text { non-dominated sorting genetic algorithm } \\ \text { PEC } & \text { purchased equipment cost } \\ \text { PUMP } & \text { ORC pump } \\ \text { REGEN regenerator } \\ \text { s } & \text { isentropic } \\ \text { tot } & \text { total } \\ \text { wat } & \text { water } \\ \text { wf } & \text { working fluid }\end{array}$

Greek symbols

$\begin{array}{ll}\varepsilon & \text { exergy efficiency } \\ \varepsilon f_{H E} & \text { effectiveness } \\ \eta & \text { energy efficiency } \\ \eta_{P U M P} & \text { ORC pump isentropic efficiency } \\ \eta_{T} & \text { ORC turbine isentropic efficiency } \\ \phi & \text { maintenance factor } \\ \psi & \text { specific flow exergy, } \mathrm{kJ} / \mathrm{kg}\end{array}$

\section{References}

[1] W. J. Ludikhuize, Special report: Research on new thermal treatment processes for domestic refuse in the Netherlands, Resour Recov Conserv, 5 (1980) 267-274.

[2] H. Wall, E. Waltz, A. Verdouw, Fuel savings in sewage sludge incineration, Waste Manage Res, 2 (1984) 205-225.

[3] S. Sakai, M. Hiraoka, N. Takeda, I. Ohhama, System design and full-scale plant study on a drying-incineration system for sewage sludge, Water Sci Technol, 21 (1989) 1453-1466.

[4] M. Hassebrauck, G. Ermel, Two examples of thermal drying of sewage sludge, Water Sci Technol, 33 (1996) 235242.

[5] P. Thipkhunthod, V. Meeyoo, P. Rangsunvigit, B. Kitiyanan, K. Siemanond, T. Rirksomboon, Predicting the heating value of sewage sludges in Thailand from proximate and ultimate analyses, Fuel, 84 (2005) 849-857.

[6] P. Stasta, J. Boran, L. Bebar, P. Stehlik, J. Oral, Thermal processing of sewage sludge, Appl Therm Eng, 26 (2006) 1420-1426.

[7] T. Taruya, N. Okuno, K. Kanaya, Reuse of sewage sludge as raw material of Portland cement in Japan, Water Sci Technol, 46 (2002) 255-258.

[8] T. Murakami, Y. Suzuki, H. Nagasawa, T. Yamamoto, T. Koseki, H. Hirose, S. Okamoto, Combustion characteristics of sewage sludge in an incineration plant for energy recovery, Fuel Process Technol, 90 (2009) 778-783.

[9] B. Khiari, F. Marias, J. Vaxelaire, F. Zagrouba, Incineration of a small particle of wet sewage sludge: A numerical comparison between two states of the surrounding atmosphere, J Hazard Mater, 147 (2007) 871-882.

[10] J. Werther, T. Ogada, Sewage sludge combustion, Prog Energy Combust Sci, 25 (1999) 55-116.

[11] P. L. Chem, J. A. Hudson, Incineration - Is there a case? Water Environ J, 19 (2005) 286-295.

[12] S. Werle, R. K. Wilk, A review of methods for the thermal utilization of sewage sludge: Polish perspective, Renewable Energy, 35 (2010) 1914-1919.
[13] Y. Cao, A. Pawlowski, Sewage sludge-to-energy approaches based on anaerobic digestion and pyrolysis: Brief overview and energy efficiency assessment, Renew Sust Energ Rev, 16 (2012) 1657-1665.

[14] M. Horttanainen, J. Kaiko, R. Bergman, M. PasilaLehtinen, J. Nerg, Performance analysis of power generating sludge combustion plant and comparison against other sludge treatment technologies, Appl Therm Eng, 30 (2010) 110-118.

[15] S. Li, Y. Li, Q. Lu, J. Zhu, Y. Yao, S. Bao, Integrated drying and incineration of wet sludge in combined bubbling and circulating fluidized bed units, Waste Manage, 34 (2014) 2561-2566.

[16] J Zhou, Y. Yao, Q. Lu, M. Gao, Z. Ouyang, Experimental investigation of gasification and incineration characteristics of dried sewage sludge in a circulating fluidized bed, Fuel, 150 (2015) 441-447.

[17] M. C. Samolada, A. A. Zabaniotou, Comparative assessment of municipal sewage sludge incineration, gasification, and pyrolysis for a sustainable sludge-to-energy management in Greece, Waste Manage, 34 (2014) 411-420.

[18] H. Ahn, D. Kim, Y. Lee, Combustion characteristics of sewage sludge solid fuels produced by drying and hydrothermal carbonization in a fluidized bed, Renewable Energy, 147 (2020) 957-968.

[19] M. Schnell, T. Horst, P. Quicker, Thermal treatment of sewage sludge in Germany: A review, J Environ Manage, 263 (2020) 110367.

[20] A. Abusoglu, A. Anvari-Moghaddam, J. M. Guerrero, Producing bio-electricity and bio-heat from urban sewage sludge in Turkey using a two-stage process, $5^{\text {th }}$ International Conference on Power Generation Systems and Renewable Energy Technologies (PGSRET 2019), August 26-27, 2019, Istanbul, Turkey. DOI:10.1109/PGSRET.2019.8882699

[21] N. Gao, K. Kamran, C. Quan, P. T. Williams, Thermochemical conversion of sewage sludge: A critical review, Prog Energy Combust Sci, 79 (2020) 100843.

[22] D.K. Sarkar, Thermal Power Plant: Design and Operation, ISBN: 978-0-12-801575-9, Elsevier Inc, 2015.

[23] F. Scala, Fluidized bed technologies for near-zero emission combustion and gasification, ISBN: 978-0-85709880-1, Woodhead Publishing Ltd, 2013.

[24] M. R. Taib, J. Swithenbank, V. S. Nasserzadeh, M. Ward, D. Cottam, Investigation of sludge waste incineration in a novel rotating fluidized bed incinerator, Process Saf Environ Prot, 77 (1999) 298-304.

[25] W. Y. Wong, Y. Lu, V. S. Nasserzadeh, J. Swithenbank, T. Shaw, M. Madden, Experimental investigation into the incineration of wool scouring sludges in a novel rotating fluidized bed, J Hazard Mater, 73 (1999) 143-160.

[26] J. V. Caneghem, A. Brems, P. Lievens, C. Block, P. Billen, I. Vermeulen, R. Dewil, J. Baeyens, C. Vandecasteele, Fluidized bed waste incinerators: Design operational and environmental issues, Prog Energy Combust Sci, 38 (2012) 551-582.

[27] A. Shukrie, S. Anuar, A. Alias, Heat transfer of alumina sands in a fluidized bed combustor with novel circular edge 
segments air distributor, Energy Procedia, 75 (2015) 17521757.

[28] R. Yan, T. D. Liang, L. Tsen, Case studies - Problem solving in fluidized bed waste fuel incineration, Energ Convers Manage, 46 (2005) 1165-1178.

[29] W. A. W. A. K. Ghani, A. B. Alias, R. M. Savory, K. R. Cliffe, Co-combustion of agricultural residues with coal in a fluidized bed combustor, Waste Manage, 29 (2009) 767-773.

[30] F. Burgess, P. D. W. Lloyd, P. S. Fennell, A. N. Hayhrust, Combustion of polymer pellets in a bubbling fluidized bed, Combust Flame, 158 (2011) 1638-1645.

[31] B. Liu, X. Yang, W. Song, W. G. Lin, Process simulation of formation and emission of $\mathrm{NO}$ and $\mathrm{N}_{2} \mathrm{O}$ during decoupling combustion in a circulating fluidized bed combustor using Aspen Plus, Chem Eng Sci, 71 (2012) 375391.

[32] Y. Koç, H. Yağlı, A. Koç, Exergy analysis and performance improvement of a subcritical/supercritical organic Rankine cycle (ORC) for exhaust gas waste heat recovery in a biogas fuelled combined heat and power (CHP) engine through the use of regeneration, Energies, 12 (2019) $1-22$.

[33] S. Safa, K. Mobini, M. H. Khoshgoftar Manesh, Thermal and Exergetic Study of the Integrated "Multi-Effect Desalination"- "Solar Rankine Cycle" System for the Iranian Southern Coastal Regions, Int J of Thermodynamics, 24 (1) (2021) 31-52.

[34] G. Eksi, F. Karaosmanoglu, Combined bioheat and biopower: A technology review and an assessment for Turkey, Renew Sust Energ Rev, 73 (2017) 1313-1332.

[35] R. Strzalka, D. Schneider, U. Eicker, Current status of bioenergy technologies in Germany, Renew Sust Energ Rev, 72 (2017) 801-820.

[36] A. Abusoglu, A. Tozlu, A. Anvari-Moghaddam, District heating and electricity production based on biogas produced from municipal WWTPs in Turkey: A comprehensive case study, Energy, $223 \quad$ (2021) https://doi.org/10.1016/j.energy.2021.119904

[37] E. Ozahi, A. Tozlu, A. Abusoglu, Thermoeconomic multi-objective optimization of an organic Rankine cycle (ORC) adapted to an existing solid waste power plant, Energy Convers Manage, 168 (2018) 308-319.

[38] E. Ozahi, A. Abusoglu, A. Tozlu, A comparative thermoeconomic analysis and optimization of two different combined cycles by utilizing waste heat source of an MSWPP, Energy Convers Manage, 228 (2021) 113583.

[39] Çengel, Y. A., \& Boles, M. A. Thermodynamics: An engineering approach. Boston: McGraw-Hill (2001).

[40] D. Mignard, Correlating the chemical engineering plant cost index with macro-economic indicators, Chem. Eng. Res. and Des., 92 (2014) 285-294.

[41] M. Jradi, S. B. Riffat, Comparative thermodynamic and techno-economic assessment of green methanol production from biomass through direct chemical looping processes, J of Clean. Prod., 321 (2021) 129023.

[42] D. Baruah, D. C. Baruah, Decision support system based planning of biomass gasification system for decentralised energy generation, Renew. Energy Focus, 38 (2021) 22-35.

[43] http://www. http://www.asimptote.nl/software/cycletempo/cycle-tempo-model-examples/

[44] J. Szargut, D. R. Morris, F. R. Steward, Exergy analyses of thermal, chemical and metallurgical processes, California: Hemisphere Publishing Co., (1988).

[45] E. Cartmell, P. Gostelow, D. Riddell-Black, N. Simms, J. Oakey, J. Morris, Biosolids - A fuel or a waste? An integrated appraisal of five co-combustion scenarios with policy analysis, Environ Sci Technol, 40 (2006) 649-658.

[46] P. Stasta, J. Boran, L. Bebar, P. Stehlik, J. Oral, Thermal processing of sewage sludge. Appl Therm Eng 26 (2006) 1420-1426.

[47] https://data.tuik.gov.tr/Bulten/Index?p=BelediyeAtiksu-Istatistikleri-2018-30667 